\title{
Behavioral Intention of Instagram as Part of Technology Acceptance
}

\author{
Mokh Adib Sultan, Mochamad Risman Purwanto Ramdhan \\ Management Study Program, Faculty of Economic and Business Education, \\ Universitas Pendidikan Indonesia \\ Bandung, Indonesia \\ diebzoeltan@gmail.com
}

\begin{abstract}
This study aimed to test the effect of performance expectancy, effort expectancy and social influence towards Instagram's behavioral intention. The study used descriptive and verifiable approach by online survey and causal design methods. The data were collected based on a 100 Instagram followers of @infobdgcom as the respondents. The study used validity testing, reliability testing, classical assumption testing, and multiple linear regression analysis. The results showed that partially there was a significant positive effect between Performance Expectancy towards Behavioral Intention, and Social Influence towards Behavioral Intention. Yet, Effort Expectancy had no significant positive effect towards Behavioral Intention on Instagram. In addition, Performance Expectancy, Effort Expectancy, and Social Influence had simultaneously influenced Behavioral Intention.
\end{abstract}

Keywords- Performance Expectancy, Effort Expectancy, Social Influence, Behavioral Intention, Instagram

\section{INTRODUCTION}

Instagram had enormous potentials to make other social media users switch and become more active in using Instagram. Some contributing factors that make people use Instagram include others' invitation to use Instagram, the increasing use of Instagram-based activities, and many others. As a result to this, the number of Instagram users continues to increasingly grow and to be the highest among other social media. The present study aimed to investigate what factors which contribute to the growing popularity in using the Instagram.

Previous research showed a number of determining factors in the use of a certain social media, including performance expectancy, effort expectancy, social influence and facilitating conditions based on the Unified Theory of Acceptance and Use of Technology (UTAUT) [1]. According to the research, there are four factors in UTAUT that influence the use of LINE as a social media. Thus, the present study attempted to investigate the influential factors in UTAUT to the use of Instagram.

The present study was based on several previous research on factors that influence behavioral intention conducted by ref [2] - [7]. The research conducted showed a significant positive correlation between performance expectancy, effort expectancy and social influence towards behavioral intention. Other studies showed that only performance expectancy had no significant influence towards behavioral intention ref [2] and [4].

The other research found that the level of convenience in using a system (effort expectancy) had no significant influence on behavioral intention. Besides, the level of acceptance of users towards Case Tools in analyzing and designing a system had no significant influence to behavioral intention [7].

The above previous research showed some differences on the results of UTAUT. Thus, this present study investigates more deeply on variables in UTAUT whether the variables are the factors that support the use of Instagram or whether there is a factor that has no influence on Instagram behavioral intention. The purpose of the study is to examine the influence of Performance Expectancy, Effort Expectancy, and Social Influence towards behavioral intention on Instagram simultaneously.

\section{LITERATURE REVIEW}

UTAUT (Unified Theory of Acceptance and Use of Technology) is a model of the acceptance of technology developed [2]. The model of UTAUT was developed to obtain a unified view of user acceptance, which were based on previously developed models, such as Theory of Reason Action (TRA), Theory Acceptance Model (TAM), Theory of Planned Behavior (TPB), Combined TAM and TPB (C-TAMTPB), Innovation Diffusion Theory (IDT), Social Cognitive Theory (SCT), Motivational Model (MM), and Model of PC Utilities (MPCU) [2].

UTAUT is proven to be more successful in giving explanation up to $70 \%$ variety of users. After evaluating the eight models, that research found seven initial constructs as significant direct determinants towards behavior intention or use behavior in one or more models. The constructs were performance expectancy, effort expectancy, social influence, facilitating conditions, attitude toward using technology, anxiety and self-efficacy [2].

After further examination, also found that there were four main constructs that played an important role as direct determinants of behavioral intention and use behavior, including performance expectancy, effort expectancy, social influence, and facilitating conditions. On the other hand, other constructs were not significant as direct determinants of behavioral intention 


\section{A. Performance Expectancy}

Performance expectancy is defined as a degree to which an individual believes that the use of a system will help him to gain advantages in the performance of his job. This concept illustrates the advantages of a system for users related to perceived usefulness, extrinsic motivation, job fit, and relative advantage [2].

Behavioral intention in information technology is defined as users' degree of intention to use a system continuously with the assumption that they have the access to information. If users gain advantages from the use of information technology, their behavioral intention to use the technology will arise to improve their performance.

Previous research conducted that indicated the influence of performance expectancy towards behavioral intention. It showed that performance expectancy had positive significant influence towards behavioral intention [3].

As a result, the first hypothesis in this study is:

H1 : Performance Expectancy will have an influence on Behavioral Intention of Instagram.

\section{B. Effort Expectancy}

Effort expectancy is the degree of ease related to users' use of technology to reduce time and energy in performing certain activities. This variable is formulated based on three key constructs previously developed theories, namely perceived ease of use in TAM model, complexity of Model of PC utilization, and perceived ease of use in Innovation Diffusion Theory (IDT) [2]..

The ease of technology use will arise individual intention that the system provides benefits and creates a sense of comfort [2]. Another research also identified that the ease of

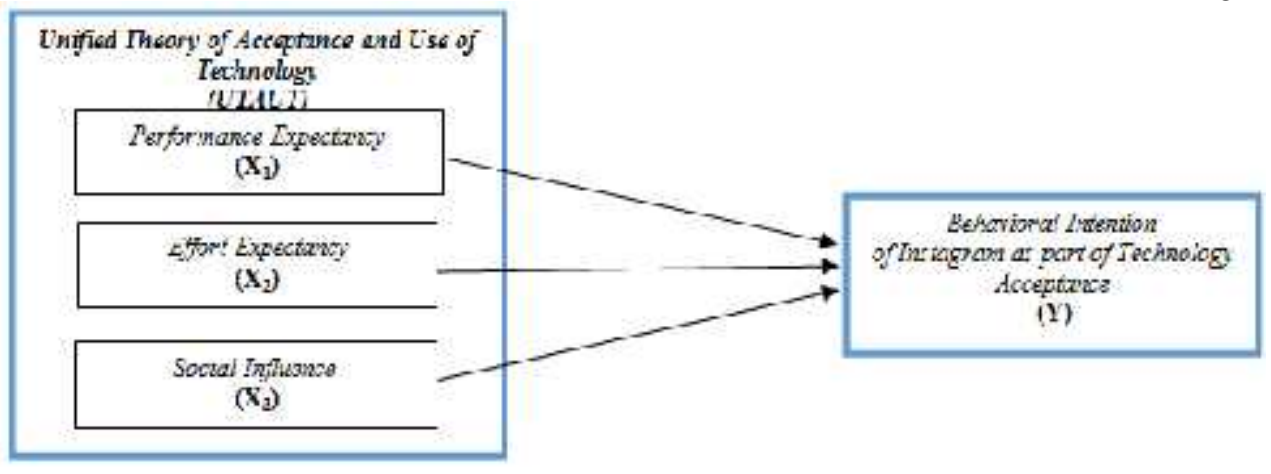

Fig. 1. Framework

\section{Behavioral Intention of Information Technology}

Behavioral intention is defined as users' likelihood to use information system continuously with the assumption that they have access to information. An individual intends to use an information system if the system has one, some, or even all three key constructs [2]. If a user uses an information technology to improve his job performance (performance expectancy), the technology can be used easily (effort technology use had an influence on behavioral intention, which was consistent the study of ref [2]. Showing that effort expectation had a significant influence on behavioral intention of information technology.

Other studies showed similar results that effort expectancy had a positive significant influence on behavioral intention (Bandyopadhyay \& Fraccastoro, 2007; Marchewka, et al., 2007). As a result, the second hypothesis to this study is:

H2 : $\quad$ Effort Expectancy will have an influence on Behavioral Intention of Instagram.

\section{Social Influence}

Social influence can be defined as the extent to which an individual perceives that significant others (e.g. family and friends) believe that the individual should use a new technology (Venkatesh, et al., 2003). The social influence is shown by the support from colleagues, superiors, and organization.

The positive significant relationship among users' social influence, such as the amount of support from colleagues, senior managers, directors, and organization. It is consistent with the study of [8], [2]. Showing social factors had a positive significant relationship on behavioral intention.

Some studies suggested tha social factors had a positive significant influence on behavioral intention [3], [4]. Thus, the third hypothesis is that

H3 : $\quad$ Social Influence will have an influence on Behavioral Intention of Instagram.

And the following hypothesis is that

H4 : Performance Expectancy, Effort Expectancy, and Social Influence, will have a simultaneous influence on Behavioral Intention of Instagram. 
The samples of the study were 100 respondents, and sampling technique was non probability sampling, using purposive sampling. The samples were selected as active users of Instagram and @infobdgcom followers.

\section{RESULT}

\section{A. The results of quality data testing}

Based on the validity testing using factor analysis, all items in the instrument to measure variables, such as performance expectancy (X1), effort expectancy (X2), social influence (X3), and behavioral intention (Y) had met the criteria of factor analysis with MSA index in KMO and Bartlett's test was more than 0.5, with significance of $>0.05$, and factor loading was more than 0.5 . This result showed that all items in the instrument were valid.

Reliability testing using alpha cronbach from four variables showed that the values of the variables were higher than critical value (0.70), showing performance expectancy (X1) 0.965, effort expectancy (X2) 0.942, social influence (X3) 0.825 , and behavioral intention (Y) 0.811 . Thus, the instrument was reliable.

\section{B. The Results of Multiple Linear Regression Analysis}

Regression analysis was used to predict or test the effect of independent variables on the dependent variable. Results of multiple regression analysis can be seen from Table 1.

The results of the final equation obtained from the multiple linear regression analysis of the influence of performance expectancy (X1), effort expectancy (X2), and social influence (X3) on behavioral intention (Y), is as follows:

$$
\mathrm{Y}=2,219+0,096 \mathrm{X} 1+0,157 \mathrm{X} 2+0,395 \mathrm{X} 3
$$

\section{The Results of Partial Hypothesis Testing}

The Influence of Performance Expectancy on Instagram's Behavioral Intention

Based on the results of multiple linear regression analysis in Table 1, it can be seen that the performance expectancy $t$ value (X1) was 2.900, larger than $t$ table value of the significance of $10 \%$, which was 1.290340 . The gained significance level was less than 0.10 , which was 0.005 . It is thus known that Hol was rejected, and Hal was accepted, meaning that there was a significant influence of Performance Expectancy on Instagram's Behavioral Intention.

The results are consistent with previous research by ref [2] - [3] suggesting that performance expectancy variable had positive significant effect on behavioral intention.

The Influence of Effort Expectancy on Instagram's Behavioral Intention

Table 1 showed $\mathrm{T}$ value of effort expectancy variable (X2) was 1.422 and significance level value obtained was 0.158 . T table with a significance level of $10 \%$ was 1.290340 .

Based on these values, it can be seen that the $t$ value 1.422 was greater than t table 1.290340 and the level of significance of $t$ value was greater than the significance level used $(10 \%)$.
This indicated that the effort expectancy variable (X2) did not significantly influence the behavioral intention (Y). Therefore, the hypothesis Ho2 was accepted, while the hypothesis Ha2 was rejected. Thus, there is no significant effect between Effort Expectancy and Instagram's Behavioral Intention.

TABLE I. The ANALYSIS OF MUlTIPLE LiNEAR REGRESSION COEFFICIENTS

\begin{tabular}{|c|c|c|c|c|c|}
\hline \multirow[b]{2}{*}{ Modol } & \multicolumn{2}{|c|}{$\begin{array}{l}\text { Unstandardized } \\
\text { Coefficieuts }\end{array}$} & \multirow{2}{*}{$\begin{array}{l}\text { Standardized } \\
\text { Cosfficients } \\
\text { Deta }\end{array}$} & \multirow[b]{2}{*}{$\tau$} & \multirow[b]{2}{*}{ Sig. } \\
\hline & I & Std. Enror & & & \\
\hline 1 (Coustant) & 2.219 & .869 & & 2.495 & .014 \\
\hline$x$ & $\partial 9 t i$ & $63 ;$ & 312 & 2900 & 005 \\
\hline$x \geqslant$ & 157 & 110 & 174 & 1422 & 158 \\
\hline$\times 7$ & $30-5$ & 132 & วดะ & $; n 0 ?$ & 007 \\
\hline
\end{tabular}

Source: Data Analysis using Data IDM SPSS Statistics 19 (2015).

The above hypothesis was inconsistent with the research of ref [2] stating that the effort expectation had a significant relationship with behavioral intention. Later this hypothesis also rejected the idea of ref [3], as well as ref [4], in which their research showed that the effort expectancy had positive significant effect on behavioral intention.

However, the other research found similar results with this hypothesis, namely, the level of ease associated with the use of a system (effort expectancy) did not have a significant influence on behavioral intention [6]. In addition, research which examined user acceptance of the Case Tools in analyzing and designing a system, also found no significant effect [7].

There was a presumption that the insignificant influence between the Effort Expectancy and Behavioral Intention in this study probably because this time Instagram has been frequently used by the public for personal or for business activities. It is based on the number of active users of Instagram, reaching $23 \%$ of GWI survey. Thus, the respondent did not consider whether it is difficult or easy to use Instagram. The respondents think that Instagram needs to be used in conducting business activities.

\section{The Influence of Social Influence on Instagram's Behavioral Intention}

The comparison between $\mathrm{t}$ values on social variables influence (X3) with $\mathrm{t}$ table was 3.002 to 1.290340 and a significance level of 0.003 with 0.10 or $10 \%$. By knowing these comparisons, it can be seen that the $t$ value was greater than t table, as well as the significance level values obtained in multiple linear regression analysis of the influence of social variables (X3) was less than the specified level of significance which is $10 \%$. Thus, the hypothesis Ho3 was rejected, and Ha3 was accepted, indicating that there was a significant difference between Social Influence on Instagram's Behavioral Intention. 
The hypothesis was consistent with the study of ref [2] which stated a significant positive relationship between social factors and interest of the use of information technology. In addition, the study found a significant positive relationship between social factors of the system users, in which the social factors were in the form of support shown by coworkers, senior managers, leaders and organizations [8].

Also suggested that social influence had a significant positive effect on behavioral intention [3], and also showed that social influence proved to have a significant positive influence on behavioral intention [4].

TABLE II. TESTING OF F-STATISTIC

\begin{tabular}{|c|c|c|c|c|c|c|}
\hline \multicolumn{7}{|c|}{ ANOW $4^{b}$} \\
\hline \multirow{2}{*}{\multicolumn{2}{|c|}{ Minter }} & Sern of & & Msan & & \\
\hline & & Sylitire: & \pm 1 & Stpiare & $\bar{F}$ & Siz \\
\hline & Remession & 1748.777 & 3 & 582.926 & 108.457 & giont \\
\hline & Rasidual & $215,9+3$ & 96 & $2.3 / 2$ & & \\
\hline & 'Tots: & 2264,120 & $\%$ & & & \\
\hline
\end{tabular}

\section{E. The Results of Simultaneous Hypotheses Testing}

Based on simultaneous hypothesis testing shown in Table 2, the obtained data showed of the total sample of 100 respondents, and then the value of $\mathrm{F}$ in this study was greater than the value $108.457 \mathrm{~F}$ table, which was 2.141730 . The significant value of $\mathrm{F}$ also showed the value of 0.000 which was smaller than $\alpha$ used (10\%), indicating that there was a significant effect on variables of performance expectancy (X1), effort expectancy (X2), and social influence (X3) simultaneously on behavioral intention (Y).

In addition, the obtained determination coefficient (Adjusted R-Square) was at 0.765 . This value means that $76.5 \%$ of $\mathrm{Y}$ variable has been affected by the variables performance expectancy (X1), effort expectancy (X2), and social influence (X3), while the remaining $23.5 \%$ was influenced by other factors beyond the factors examined by the author. Thus, the variables that formed behavioral intention of Instagram users had a high impact.

\section{CONCLUSION}

Based on the research on the influence of performance expectancy, effort expectancy and social influence on behavioral intention of Instagram users who become followers of @infobdgcom, it can be concluded that the partial results of the study showed that performance expectancy had effect on behavioral intention, as well as social influences had effect on behavioral intention. However, effort expectancy showed no significant influence on behavioral intention.

Then, the influence of Performance Expectancy, Effort Expectancy, and Social Influence on Instagram's behavioral intention conducted simultaneously showed that there was an influence between the variables of performance expectancy (X1), effort expectancy (X2), and social influence (X3) on behavioral intention (Y) of Instagram.

\section{REFERENCES}

[1] Listyo \& Lisandy. (2014). Factors Affecting the Use Behavior of Social Media Using UTAUT 2 Model. Proccedings of the First Asia Pacific Conference on Global Business, Economics, and Social Sciences (AP14SINGAPORE Conference).

[2] Venkatesh, Viswanath. (2003). User Acceptance of Information Technology: Toward Unified View. Jurnal MIS Quarterly, Vol. 27, No. 3, hlm. 425-478.

[3] Bandyopadhyay K, and Fraccastoro K A (2007), "The Effect of Culture on User Acceptance of Information Technology", Communications of the Association for Information Systems, Vol. 19.

[4] Marchewka, J., Liu, C., \& Kostiwa, K. (2007). An application of the UTAUT model for understanding student perceptions using course management software. Communications of the IIMA, 7(2), 93-104.

[5] Al-Awadhi, S. and A. Morris, 2008. The Use of the UTAUT Model in the Adoption of E-government Services in Kuwait. In Proceedings of the 41 Hawaii International Conference on System Sciences

[6] Sedana, Nyoman \& Wijaya, Wisnu. (2010). UTAUT Model for Understanding Learning Management System. Internetworking Indonesia Journal Vol. 2, No. 2, hlm. 27-32.

[7] Dasgupta, S., Haddad, M., Weiss, P., dan Bermudez, E., 2007, "User Acceptance of Case Tools in System Analysis and Design: an Empirical Study", Journal of Informatics Education Research, Vol. 9, No. 1, pp. $51-78$

[8] Thompson, R. L., Higgins, C. A., and Howell, J. M. "Personal Computing: Toward a Conceptual Model of Utilization," MIS Quarterly (15:1), 1991, pp. 125-143. 